\title{
The Motor Coordination Reasoning in Acting Dancer's Performance Improvement and Injury Prevention
}

\author{
Kaanda Nabilla Souza Gontijo ${ }^{1}$, Carla Itatiana Bastos de Brito ${ }^{2}$, Cláudia Tarragô Candotti ${ }^{3 *}$ and Adriane Vieira ${ }^{4}$ \\ ${ }^{1}$ Graduate Program in Human Movement Sciences, Federal University of Rio Grande do Sul, Brazil
}

${ }^{2}$ Department of Physiotherapy, IPA Methodist University Center, Brazil

${ }^{3}$ Ph.D. Professor of the Graduate Program in Human Movement Sciences, Federal University of Rio Grande do Sul, Brazil

${ }^{4}$ School of Physical Education, Federal University of Rio Grande do Sul, Brazil

Submission: March 16, 2018; Published: March 27, 2018

*Corresponding author: Cláudia Tarragô Candotti, Ph.D. Professor of the Graduate Program in Human Movement Sciences, Federal University of Rio Grande do Sul, Brazil; Tel: 55 (51) 3308-5822; Fax: +55 (51) 3308-5843; Email: claudia.candotti@ufrgs.br

\begin{abstract}
Many injuries that affect classical dancers are caused by compensations made to overcome anatomical limitations, which cause a proper coordination loss between the body segments. This lesions appearance, ultimately, results in people giving up on the practice even after different types of rehabilitation conventional treatments application. Given this reality, we argue for a physical therapy line focused on posture and movement re-education, based on Motor Coordination (MC), as described by Piret and Béziers, since we consider it has great potential not only to improve the dancers' performance, but to prevent and treat injuries. So our goal in this article is to express our opinion on how MC principles can contribute to the classical ballet teaching-learning-training process and to the dancer's preventive treatments and rehabilitation with regard to their lower limbs arrangement.
\end{abstract}

Keywords: Dance; Posture; Joint Instability

\section{Introduction}

The physical demands present in several techniques and types of dance often result in injuries which, in turn, limit the dancers' capacity to perform [1], jeopardizing their careers' success and smooth progress. Prolonged training periods, insufficient rest, inadequate floors, difficult choreographies, insufficient warm up and a reflective body awareness lack are among the factors that contribute to these injuries $[2,3]$.

The lesions, be them acute or from overuse, are often related to a perception and coordination loss of the segments that make up the lower limbs, associated with an attempt to overcome anatomical limitations in the dance teaching-learning-training process [4-7]. Unfortunately, it is common that these lesions appearance eventually lead the dancer to abandon their practice and, because of that, we consider it relevant to further the knowledge and to disseminate principles such as the Motor Coordination by Piret [8], which focus on these professionals' posture and movement re-educating. We also believe that preventive and therapeutic interventions based on Motor Coordination can contribute to the classical ballet teachinglearning-training process, since, specifically in the lower limbs, this approach acts directly on the dancers proprioception, on their body perception (involving psychomotor gains) and on their knees torsional stabilization, which are considered to be key points for the segments arrangement/coordination that are most used in this type of dance.

Introducing it, then, in more detail, we have, in the 1980s, as the first record in the literature, the "La Coordination Motrice: Aspect Mecanique de L'Organisation Psycho-Motrice de L'Homme" (Motor Coordination: Human Psychomotor Organization Mechanical Aspects) book publication, written by the French motor psychology experts Suzane Piret and Marie Madeleine Béziers [8] and translated to Portuguese in 1992. According to Santos [9], this line of interpretation and intervention on posture and movement is able to fill a gap in areas that study and deal with kinesiology, because it looks at the natural psychomotor human development being from conception to adulthood. For Piret and Béziers, this development happens with the gestures perception and repetition we make in order to feed ourselves and walk, basic movements that start in intrauterine life. For these authors, this repetition throughout life and our 
activities shape and inscribe in our bone anatomy the right or compensatory paths we choose to accomplish each of these and many other movements. In short, according to Santos, the different reasoning that Motor Coordination brings regarding the human body fills the movement "school" gap that is based on the anatomical and psychomotor human development beings from womb to adulthood, encouraging the creation and propagation of ideas for exercises and therapeutic approaches that are able to reach different fields such as dance, physical education, physical therapy and orthopedics, among others.

Piret [8] consider that Motor Coordination comes from a body segments torsional organization that allows the balance tension installation between antagonistic muscle groups, organized by specific muscles called tension conductors. These muscles, in turn, would be able to respond to neurological commands linked to automatic and proprioceptive functions such as holding, walking and breathing, that is, nothing more and nothing less than the natural basic functions we need to perform throughout life. This torsional organization, according to them, is based on the tension from twisting and winding aspherical elements through these driver muscles which, from head to hand and from head to foot, unite the whole body in a tension that determines its form and movement.

About the lower limbs organization, the authors show the knee joint as a central point (and an inversion point) between the external femoral torsion and the internal tibial torsion (accompanied by the fibula), conducted by the iliopsoas muscles, the Sartorius and the tibialis anterior in an antagonistic manner. In other words, this antagonistic opposition happens through the organizational tension that keeps the tibia rotating internally, as opposed to the tension for external rotation exerted on the femur by the muscles mentioned previously, resulting in the bone segments alignment and knee torsional stabilization, either for static positions or movement. Therefore, according to these authors, this antagonism, when balanced, is what prevents the patella from being medialized while the feet are pointed outward during the simple act of walking. This antagonistic twist imbalance, then, can tense and stress ligaments like the medial collateral and cruciate ligaments, disorganizing the lower limbs and, in addition to damaging the walking function, also harming other movements that we perform or, as in the dancers case, all technical steps required by ballet.

Because this dance requires positions with lower limbs external rotation, called en dehors or turnout, consequently, the knees are the most commonly affected by injuries among the practitioners [10-19]. These injuries are caused exactly by the fact that dancers lose the tibias internal rotation and turn them externally, along with the femurs, so as to aesthetically present the final turnout angle position in $180^{\circ}$. So, this action can injure the knees and all the other structures that compose these body segments. Béziers [8] believe to be the natural for a human mechanics torsional organization balanced, based on our psychomotor development.
Based on the facts presented above, the goal of this paper is to demonstrate how the principles from the torsional organization proposed by the Motor Coordination reasoning may contribute both for the dance teaching-learning-training process (classical ballet) and for treatments aimed at preventing and rehabilitating dancers regarding their lower limbs. For that, we organized this opinion article initially presenting the mechanical characteristics that guide the classical dance art, followed by commentaries about the repercussion of its practice on the dancers' musculoskeletal structure, especially the knee joints. After that, we talk about the principles that guide the Motor Coordination kinesiology and psychomotor reasoning, presenting them one by one. Lastly, we discuss the reasons that led us to propose the exercises practice based on Motor Coordination reasoning as an important component in the dance teaching-learning-training process, both for technical improvement and for preventing injuries in classical dancers, but stating the need for further research that can evidence this proposal efficacy.

\section{Classical Ballet and the Lower Limbs Organization}

The dance practice generally consists of the repetitive movements use. So, understanding how the muscles used in these movements are recruited and put into action and what the adequate psychomotor execution of these movements would be, not only increases the people ability practicing them but also minimizes the injuries risk [20]. Thus, we can say that the movements repetition in dance may cause problems in posture due to the process performed for the gestures automatization that compose it [21-23]. Generally, Watson [24], Juli [25] and Motta [26] presented data that are in agreement with this scenario, emphasizing that the risks to the organism caused by any repetitive physical activity affect the structures because of the amount and the movements specificity performed and because of adequate or inadequate performance.

Classical ballet is part of the features previously described and is regarded as a cyclical and repetitive physical activity with regard mainly to its training characteristics [27]. Its practice requires specific physical performance of people who practice it and constantly requires aesthetic movements' patterns with a wide range of motion that go beyond the anatomical limits [28]. These requirements make classical ballet different from other sporting activities, causing classical dancers to be a peculiar group of associated lesions [29-38]. In a study with 324 professional dancers, for example, almost $50 \%$ of them reported that they lost one to twenty-one days of exercise due to musculoskeletal injuries each year and that $90 \%$ of these injuries involved the lumbar-pelvic region and lower limbs [39].

Focusing a little more on the requirements and classical ballet technical principles, there is the fact that professional classical dancers must be very skilled artists in order to survive the highly dance industry competitive nature, as reported by Weiss [40], an industry is that requires a maximum and ideal 
turnout, as a prerequisite. The turnout is characterized as the maximum lower limbs external rotation, and it is of great aesthetic importance to classical dance [41]. This lower limbs positioning is considered to be the most important in classical ballet, and its primary technical goal is the achievement and maintenance of a $180^{\circ}$ angle between the feet while steps are executed or danced. However, as described in the technical literature, its origin must be in the hips external rotation and, in a smaller part, in the tibia and feet external rotation. But not all dancers are able to anatomically achieve the ideal turnout in $180^{\circ}$ using only the hips external rotation. Therefore, many use, mostly, the tibia and feet external rotation as strategies to compensate for the lack of hip joints rotational amplitude, thus creating a torsional organization loss-which ensures a good knee joint structures positioning, thus leading them to feet pronation or feet arches collapse.

So, these actions are frequently observed in classical ballet and are strongly linked to injuries in ballet dancers. They can be understood as excessive psychomotor strategies to achieve the maximum turnout that the ballet aesthetics demands, that is, the one with $180^{\circ}$ between the medial feet borders. However, this generates disturbing bone segments mechanical misalignments that form the lower limbs. These misalignments, in turn, can put the muscles, tendons, joint structures and nerves under inadequate pressure or tension, which, consequently, can cause acute or chronic lesions on dancers [42]. As an example of this fact, we mention the epidemiological study that related a $90 \%$ lesions incidence among the researched ballet dancers, with approximately $75 \%$ of these lesions affecting the lower limbs. In this same study, $40 \%$ of the lesions were connected to the foot, ankle and leg bottom part [43]. These are the areas that are commonly used to perform the compensatory movements mentioned above in order to obtain the ideal turnout in $180^{\circ}$.

Applying this technical principle to the ballet practice, we can see it during the execution of one of the most important steps from this type of dance, the plié, a basic step found in all classical ballet technical movements, from the simplest to the most elaborate and complex ones. The plié depends directly on the correct turnout performance and maintenance throughout all its movement phases [44], which involve the simultaneous and coordinated flexion of the three great joints located in the lower limbs (ankles, knees and hips), always associated to the turnout and to the:

a) Adequate vertical alignment between the knee center with the second ipsilateral toe maintaining;

b) Pelvis stabilization in a neutral position maintaining; and

c) Mid foot maintaining during all three step stages (extended knees, demi-plié and grand plié $[45,46]$.

Thus, it is possible to conclude that an ideal turnout requires a specific lower limbs organization, including skeletal alignment, joint mobility and soft tissues flexibility, besides years of training in order to achieve, when possible and if possible, the maximum angle of $180^{\circ}$ between the feet without generating compensations, as has been presented. That is, if the ideal anatomical resources are not available due to structural limitations or lack of training, mainly regarding the dancers' hip joints, compensations can be developed which can put dancers in risk of acute or chronic lesions, as mentioned earlier $[47,48]$. However, between the hips external rotation and the feet to perform the turnout, coordinated or not, there will always be a fundamentally important joint for any human being: the knees.

Thus, we reach the key point that supports all the reasons for this paper: The statement that the classical ballet practice can be improved with a preventive therapeutic intervention based on the Motor Coordination principles. We will present the lower limbs major joints, the knees, as a starting point of analysis to support this statement.

\section{The Key Point: The Knees}

The knees are intermediary joints located between the hips and the ankles and which present high musculoskeletal vulnerability, mainly due to where they are located, but also because they have limited movement amplitude regarding planes and axes, because of the stable congruence lack between their articular surfaces and because of the intrinsic muscle low amount that they possess. From a biomechanical point of view, during classical ballet steps-whichever ones-the knees will be protected during the maximum external rotation (turnout) when the hips positions and the feet are correct, without torsional compensations like those performed by the tibia, ankles and feet $[49,50]$.

From an anatomical point of view and according to what is postulated by the classical ballet technique, the knees should always be projected over each foot, towards the second or third toe. So if they are compensatorily located towards the medial aspect of the corresponding foot longitudinal arch, either by excessive tibia and foot external rotation or by a hips (or coxofemoral joints) external rotation deficit, incorrect twist forces will be generated in the knees, which will affect the medial meniscus, medial collateral ligaments, the patellofemoral joints, bursae, retinacula etc. while the dancer is flexing the knees (plié) or in any other situation. In addition to these lesions, associated with lower limb joints misalignments, there are other ones that also affect this important joint, such as anterior cruciate ligaments distension and/or tearing, causing an increase in joint rotational instability and knee hyperextension; and medial collateral ligament distension or tearing, compromising the medial joint stability; patella friction with the trochlear groove, resulting in patellofemoral articular cartilage wear; meniscus lacrimation or rupture; patellar tendinitis and/or chondromalacia increased incidence; jumper's knee; predisposition to patellar displacement and wear [51-58]. 
In short, for a secure basic steps execution, for example the plié - which requires knee flexion in addition to maintaining the turn out-it is essential to prioritize the knees alignment with the feet, particularly when the hips turnout is reduced. Thus, one can hypothesize that in order to prevent the aforementioned injuries, which affect the dancers' lower limbs, the hips, knees and feet alignment is essential. Moreover, it is also possible to suggest that, preventively, the dancers must comply with the maximum external rotation angle that each hip is able to perform and so, then, position their feet, so that while the knees are being flexed they are not medialized by tibias and feet external rotation excess. In contrast, preserving the lower limb joints alignment can lead to a reduction in the angle obtained between the dancers' feet on the soil, where they ate not capable of a great hip external rotation, which looks, aesthetically, like a smaller or more closed turnout, which, although safer, does not meet the physical aesthetics required by the classical ballet competitive environment. So we reach an important point to be discussed: what should be prioritized, the aesthetics or the dancers' joint and musculoskeletal health? This leads, then, to the question that guides this paper: doesn't the Motor Coordination reasoning use with aim at the lower limb joints alignment and the dancers' joint and musculoskeletal health preservation result in better conditions for seeking aesthetic perfection in classical ballet without causing injuries because of the loss of torsional organization?

To answer these questions and to support our idea regarding the preventive physical therapeutic work application benefits, together with the dancers' technical improvement using the Piret, Béziers [8] Motor Coordination principles to align and organize the lower limbs torsions, we will go into the French psychomotor therapists' approach in detail.

\section{Motor Coordination and Its Principles}

Motor Coordination can be defined as a kinesiology and psychomotor reasoning based on a torsional organization that enables the balance between bone segments and specific muscle groups called conductors, which respond to neurological commands linked to automatic and proprioceptive functions. Among these functions we find holding, walking, breathing, which, as has been mentioned before, are basic functions we need to perform throughout life. In other words, Motor Coordination can be defined as a tensions game between muscles, bones and joints, an organization for movement that enables the body to structure itself autonomously in order to relate with the environment [59].

According to Piret [8], the body is not just a tool or a mechanic structure that enables movements and is isolated from the psychic and emotional life: it is a lived body, a body mind [60], which affects and is affected, shapes and is shaped, structures and is structured by what is lived, by experiences, by relationships that it establishes with the environment and by the repetition of gestures, be them part of day to day life, artistic or sportive. The construction of knowledge, according to them, happens through the experience and perception of the body as a whole, through the appropriation of its self-organization for relating with the environment, which generates particular manners of moving, in the case of dancers, inside classrooms and on stages. The movement investigation trump card proposed by Motor Coordination is the perception study, self and environment studies, based on three notions:
a) The proprioception or structure notion;
b) The passage notion, that is, moving in space and time; and

c) The relationship notion, be it with another person, with an object or with the environment.

Thus, by comprehending these three notions and the Motor Coordination principles, one understands that it is through the motility action, that is, though action on the form, on the body, on the tensions quality, on the perception of what is lived, that the body structures and perceptions are built and transformed, that is, the proprioception. This proprioception development will serve as the solid foundation for this body to venture - without harmful imbalances - into the relationships that it will establish with the environment and with the Other, as is stated by Louppe [61], who puts the body exactly as a relation field, which knows, which thinks and which expresses itself in many ways.

Following the thinking line that the body is capable of expressing itself, thinking and knowing, it is possible to find, in the literature, studies that follow the approach by Berthoz [62], which position the movement sense as a sixth sense represented by muscle, joint and vestibular systems combination. These systems, with their sensory receptors locates in the muscles, tendons, joints and inner ear, help the body to become aware in space, to balance, to bend, to perceive changes in speed and to perceive its own movement; they are intimately connected to another sense, the sight sense. According to Bianchi [59], this is a concept or perception or proprioception example that can be transported to the body experience while dancing, because when the capacity for body perception is enlarged, each individual creates a sensory knowledge archive, vestiges and memories that are recovered and re-elaborated according with what each action asks for, at every moment. Complementing this thoughts connection and concepts, we mention what Piret [8] defined as perception: "[...] a personal endeavor in the spacetime, a personality acts", that is, the result of a particular way of experiencing and dealing with oneself.

However, before we continue with the Motor Coordination description and its principles, we raise the following question: do bodies that dance and build their movements routine around a repetitive and extreme gestures set possess this sensory and perceptive knowledge so that they can explore technical spaces and steps with the knowledge that would prevent them from injuring their muscles, tendons and joints? 
In our experience, we found more bodies adaptations to the technique than the technique to each body. This ignores the respect to each person physiology individuality whole concept, the body self-perception focused on the physical limits identification that each person has, in a preventive manner. Thus, we believe that a possible strategy for reaching the purpose raised by this question would be the possibility of allowing these bodies that dance to return to the anatomical and kinesiological fundamentals that guide the human movement when feeding, walking and breathing, just like the Motor Coordination principles-which we will present now-challenge each body to reorganize and coordinate itself. These principles use (based on kinesiology reasoning) would enable the different training type's creation, so these bodies could be built in a safe, balanced and smart way. Since the Motor Coordination genesis lies in restoring or maintaining the body's health, we believe that the authors proposal, based on personal experience, on the body structure itself, on the space-time and on the relation with the world, promotes the establishment of more perceptive and attentive states in each and every body that accepts to reestablish itself "proprioceptively" through its principles.

Bianchi [59] talked in their paper about each of the six Motor Coordination principles, which will be duly described and commented in the pages that follow in order to seek, in their definitions, the means and justifications that allow this technique application to be disseminated and absorbed by classical dancers in a preventive and therapeutic manner.

\section{Coordination Unit}

The body, according to Piret [8], is composed by various coordination units (such as arms, legs, torso-skull-pelvis, hands and feet), each one relating with and reaching the next unit, promoting a fully integrated unit. Individually, each unit is characterized by the set formed by two ball joints, one at each end, which are placed under tension to rotate in opposite directions by the major multi-articular muscles action, the movement conductor's muscles. This torsional tensioning enables flexionextension movements, generating a tension balance between the flexor and extensor muscles and a consequent dynamic, continuous and uninterrupted power transmission, that runs throughout the body in an elliptical manner.

On the knees, the torsional balance emerging from placing the plantar arch on the ground in a closed kinetic chain propagates from the tibialis anterior activation (which promotes a tibia and fibula internal rotation action, together with calcaneus external rotation) to the sartorius activation (which rotates the tibia internally and leads its synergists, present in the thigh and pelvis, to rotate the femur externally with the iliopsoas aid, present in the hip). This antagonistic relationship between the tibialis anterior and the sartorius, one acting on the tibia/fibula and the other on the femur, stabilizes the knees, which, when dynamically bent to opposite sides in a balanced way, enables that the tension between all other muscles from the lower limbs be properly propagated from the feet to the hips and vice-versa. Piret [8] believe that this tension passage between the muscles, when balanced and coordinated, enables the lower limbs movements to be performed harmonic manner, without damaging overloads. Thus, understanding this first principle and all its repercussions on the lower limbs and being aware of the recurring rotational compensations exercised during the classical ballet practice, we believe that the kinesiology reasoning regarding articular torsional balance proposed by Piret and Béziers8, has great preventive and preparatory capacity for the classical dancers public and also for other dancers, as claimed by Bianchi [59], since all of them use their lower limbs extensively.

\section{Action Inhibition}

Gesture inhibition is largely used in Motor Coordination in the search for isometric muscle work. In this work, exercised by the gravitational muscles, the tension is gradually modulated so it becomes possible to perceive how each micro-movement affects self-awareness $[8,59]$. So, when transposing this principle to dancing bodies it is possible to verify that the isometrics-seen as the basis of torsional work - leads the individuals to have time to recognize themselves and to activate all the receptors that compose the human sixth sense described by Berthoz [62], the body perception sense.

\section{Perpetual Movement, the Motor Coordination Eights}

According to Piret [8], when the body is organized, the fascicle and muscle fiber tonus starts to trail a tension propagation pathway that elongates the muscles and decompresses bones and articulations. This pathway eventually generates movement, elliptically, dynamically and uninterruptedly, which also represents the mathematical infinite symbol, chosen by them to represent this tension pathway.

So, according to Bianchi [59], the elliptical eight movement's work, which are present in all coordination units - in the skull, the pelvis, the shoulder girdle, the upper limbs and the lower limbs, causes the body to never paralyze, providing a dynamic feature to the body in waves that propagate without interruption. This continuous propagation quality gives the body even more selfawareness and balance so it can perform any and all movement that it wishes and plans to execute. Thus, leading dancers (who use all movement strategies very often, from the faster and more explosive ones to the ones that are slower and more controlled) to reach this balanced tension character through the elliptical Motor Coordination movements would help them to add more dexterity and efficacy to their movements, which would bring more harmony to their dance, since the continuity or connection between one step and the other is what makes the difference between the beginner and professional dancers performances.

\section{Motor Space-Time}

To Piret [8], the space in which the body acts is called motor space, and each gesture rhythm and duration that happen in very particular manners to each body, they call motor time. 
Thus, Motor Coordination proposes that the same gesture be tried in different planes, with different objects and relationships with space, so that one can perceive the change in this gesture form according with the space where the body is.

In the practical approach, focused on the dancers' lower limbs torsional organization, this principle is translated into the basic movement's execution-like walking phases and technical steps-on different surfaces, also changing each movement execution speed. According to Bianchi [59], it is this work with different objects, with different weights, sizes, textures and shapes, that make the perceptions more diverse and precise, that is, they train and let the motor and proprioceptive systems ready to allow the body to perform all movements while itself aware, without physical harms related to articular or muscle lack. Thus, this work has great value and it is ideal to be applied to dancers, given the demands to which their bodies are submitted and the need to maintain their motor and proprioceptive systems always active during long, and, sometimes, rapid steps sequences during classes or choreographies.

\section{Body Vectors, Structure and Dynamics}

Motor Coordination conceives two lines or strength vectors that act on the body: One is structural and the other is dynamic. The structural one indicates the body relationship with itself able to curl, to straighten and to return to balance on its own axis with the rectus muscle system action. This system connects the skull sphere with the pelvis sphere, at the opposite end, by two axes, one posterior, formed by the vertebral column and extensor muscles, and an anterior one, composed by the mandible, hyoid, sternum, pubis and flexor muscles. According to Piret [8], the opposition or antagonism between skull and pelvis are supported by an adequate muscles organization from these spheres and by the tonic balance between the muscles from the two axes, ensuring the vertebrae mobility while at the same time stabilizing the torso, so this stabilizing tension can support all and any movement on it and around it, like the torsions that will be performed with the cross-system dynamic opposition action.

In these dynamic movements, muscle action happens laterally through this second system, especially by the abdominal oblique action working with reciprocity: as one part flexes, the other extends, changing the rectum muscle system shape and creating a contra lateral opposition between skull and pelvis. Thus, according to the authors, the cross-system action enables the body to stop curling just on itself and start to create relationships with the environment, which is characterized as a relational vector. This vector, acting on the torso, thanks to the multi-articular and longitudinal muscles presence and action, called motion conductors muscles because of their ability to transmit tension in chain, insertion in at least two joints and opposite torsions generation - causes one coordination unit to rotate internally and the other in to rotate externally, which creates a torsion in opposition and leads the generated tension to the upper and lower limbs; so, the cross-system responsibility is to extend this movement to the limbs. With this torso stabilizing and dynamic actions interpretation in relation to the limbs, it is possible to understand why, before spinning around themselves, using their lower limbs as a basis, the dancers need to find their own axes in static postures during the teaching-learningtraining process, that is, the balances. In addition to this, the Motor Coordination authors add that understanding, through bodily action, that establishing a relationship with the other (cross-system) depends, primarily, on establishing a relationship with oneself (rectus system), which enables the understanding that the relationship with the world happens initially with the oneself perception, because, for them, only by experiencing the self is that one may experience and perceive the other.

Transposing this Motor Coordination principle to the practice, we believe that no isolated torsional organization work exclusive to the dancer's lower limbs will succeed if their body's center is not organized, that is, in reciprocal balance between the rectus and cross-systems. Thus, it is fundamental to associate the exercises that organize the lower limbs torsions with others that focus on torso stabilization and organization, like with boards in different positions and on different support surfaces.

\section{Balance}

It is in instability that balance is maintained, since balance is not fixed, but rather the continuous kinetic game result based on the relationship between opposite strengths. One of these strengths is the game between body and gravity, because gravity and the bones act pushing the body to the floor while the muscles pull it upwards. It is not a game against gravity, though, but with gravity, since balance is the result from a "[...] organization form in reverse".

In this context, the dancers lower limbs torsional organization work on unstable surfaces, from balance boards to foams and small objects, forces the body to experience instability and to find particular itself supporting ways in instability, sharpening and improving its proprioception and body reflexes. Thus, it can be noted that the dancers have a lot to win from these proprioceptive works use and application based on this and other Motor Coordination principles, since, naturally, because of the technical demands from classical ballet, they are always challenging their bodies to balance dynamically during classes and choreographies, and, as was stated by Bianchi [59], the artist body abilities demanded are different from the ones merely morphological body demanded. Construction and training are demanded of individuals who are capable to generating microperceptions, micro-differences and torsions that, any times, affect their natural operational capacities.

\section{Considerations about Motor Coordination Focused on the Dancers Performance and Treatment Improvement}

Based on the fundamentals that guide the Motor Coordination practical application [8] we observed that the work proposed here is based on the key muscle groups neuro-psychomotor and 
proprioceptive reeducation that act on the body as a whole, and which are fundamentally important for anyone who practices physical activities, including, and mainly, classical and other dancers, who take their bodies to the limit-many times going over the limit on behalf of technique, of art, of aesthetics, or of the training context and choreographic performance in which they act. Thus, we believe that, respecting the human anatomy and physiology and the each body articular biomechanics, interventions focused on the muscles spiraling strengths reorganization that act on each one of them, emphasizing the organizational torsions described by Piret [8], are valid for any type of body, especially those which take their muscles to the extreme, like classical dancers.

We emphasize that the principles described and discussed here - which are central for Motor Coordination - have been our clinical practice bases, which is the foundation of this discussion. However, we agree that these principles still need to be recognized in the scientific field, with experimental studies or clinical trials with dancers.

\section{Conclusion}

Our goal with this opinion article was to demonstrate that the torsional organization principles proposed by Motor Coordination can contribute for the dance teaching-learningtraining process (classical ballet) and for preventive and therapeutic treatments for dancers regarding their lower limbs organization. Thus, we register and describe here our justification for the constant Motor Coordination use focused on technical improvements, on the lesions prevention and treatment in classical dancers, and we suggest that it be included in the teaching-learning-training process of these individuals.

In short, what can be concluded from what we related here is that Motor Coordination aims to reorganize the muscles with the goal of not only improving neuro-psychomotor and proprioceptive coordination, but also preventing and rehabilitating lesions connected to the awareness and body control lack in the dance practice. So, this is a potential tool, capable to improving the technical dancer's performance and preventing lesions.

\section{References}

1. Welsh C, Hanney WJ, Podschun L, Kolber MJ (2010) Rehabilitation of a female dancer with patellofemoral pain syndrome: Applying concepts of regional interdependence in practice. N Am J Sports Phys Ther 5(2): 85-97.

2. Sohl P, Bowling A (1990) Injuries to dancers: Prevelance, treatment, and prevention. Sports Medicine 9(5): 317-322.

3. Markula P (2004) Tuning into one's self: Foucault's technologies of the self and mindful fitness. Sociol Sport J 21(3): 302321.18

4. Hamilton WG (1978) Ballet and your body: An orthopedist's view. Dancemagazine 6: 84-85.

5. Gantz J (1989) Evaluation of faulty dance technique patterns: A working model. Kinesiology and Medicine for Dance 12(1): 3-11.
6. Bordier G (1975) Anatomie appliquée à la danse: Le corps humain, instrument de la danse. Amphora, Paris, Europe.

7. Kushner S, Saboe L, Reid D, Penrose T, Grace M (1990) Relationship of turnout to hip abduction in professional ballet dancers. Am J Sports Med 18(3): 286-291.

8. Piret S, Béziers MM (1992) A coordenação motora: Aspecto mecânico da organização psicomotora do homem. Summus, São Paulo, Brazil.

9. Santos A (2002) A biomecânica da coordenação motora ( $2^{\text {nd }}$ edn). Editora Summus, São Paulo, Brazil.

10. Reid CC (1988) Prevention of Hip and Knee Injuries in Ballet Dancers. Sports Medicine 6(5): 295-307.

11. Silver DM, Campbell P (1985) Arthroscopic Assessment and treatment of dancer's knee injuries. Physician and Sports medicine 13(11): 7482.

12. Wohlfahrt DA, Bullock MI (1982) Turn out in ballet and its effect on the knee joints. Proceedings of the VII Commonwealth and International Conference on Sport, Physical Education, Recreation and Dance. Physiotherapy in Sport 3: 71-81.

13. Howse AJG, Hancock SH (1992) Dance technique and injury prevention. A\&C Black Publishers Limited, London, UK.

14. Stephens RE (1987) Dance Medicine a Comprehensive Guide: The young ballet dancer. Pluribus Press Inc, Chicago, USA.

15. Pozo Municio MC (1993) Ballet clásico: el “en dehors". Revista Española de Medicina dela Educación Física y el Deporte 2(3): 161-170.

16. Hincapié CA, Morton EJ, Cassidy JD (2008) Musculoskeletal injuries and pain in dancers: A systematic review. Archives of Physical Medicine and Rehabilitation 89(9): 1819-1829.

17. Barnes MA, Krasnow D, Tupling SJ, Thomas M (2000) Knee Rotation in Classical Dancers during the Grand Plié. Med Probl Perform Art 15(4): 140-147.

18. Kadel NJ (2006) Foot and Ankle Injuries in Dance. Phys Med Rehabil Clin N Am 17(4): 813-826.

19. Nilsson C, Leanderson J, Wykman A, Strender LE (2001) The injury panorama in a Swedish professional ballet company. Knee Surgery, Sport Traumatol Arthrosc 9(4): 242-246.

20. Kwon Y, Wilson M, Ryu J (2007) Analyses of the hip joint moviments in grand Rond de jambe em l'air. Journal of Dance Medicine \& Science 11(3): 93-99.

21. Gonçalves DV, Santos ARB, Duarte CR (1989) Avaliação postural em praticantes de natação: uma análise crítica. Revista Brasileira de Ciência Movimento 3(2): 16-23.

22. Caspersen CJ, Powell KE, Christenson GM (1985) Physical activity, exercise, and physical fitness: Definitions and distinctions for healthrelated research. Public Health Rep 100(2):126-131.

23. Toledo SD, Akuthota V, Drake DF, Nadler SF, Chou LH (2004) Sports and Performing Arts Medicine. Issues relating to dancers. Archives of Physical Medicine and Rehabilitation 85(3): 75-78.

24. Watson AWS (1983) Posture and participation in sport. Journal of Sports Medicine and Physical Fitness 23(3): 231-239.

25. Juli RB (1983) Acción de la sobrecarga deportiva sobre el aparelho locomotor del niño y de adolescente. Apunts 20: 85-95.

26. Motta JA, Maia JAR (1991) A postura como fator de observação na escola. Revista Brasileira de Ciências do Movimento 5(2): 36-39.

27. Prati SRA, Prati ARC (2006) Níveis de aptidão física e análise de tendências posturais em bailarinas clássicas. Revista Brasileira de Cineantropometria e Desempenho Humano 8(1): 80-87. 
28. Achcar D (1984) Balé: uma arte. Editora Ediouro, Rio de Janeiro, Brazil.

29. Klemp P, Learmonth ID, Learmonth D (1984) Hypermobility and Injuries in a Professional Ballet Company. J Sport Med 18(3): 143-148.

30. Kadel NJ, Teitz CC, Kronmal RA (1992) Stress fractures in ballet dancers. Amplied Journal Sports Medicine 20(4): 445-449.

31. Coplan JA, Coplan J (2002) Ballet Dancer's Turnout and its Relationship to Self-reported Injury. J Orthop Sports Phys Ther 32(11): 579-584.

32. Hamilton D, Aronsen P, Løken JH (2006) Dance training intensity at 1114 years is associated with femoral torsion in classical ballet dancers. Br J Sports Med 40(4): 299-303.

33. Khan KM, Bennell K, Ng S (2000) Can 16-18-year-old elite ballet dancers improve their hip and ankle range of motion over a 12-month period? Clin J Sport Med 10(2): 98-103.

34. Sherman A, Mayall E, Tasker S (2014) Can a prescribed turnout conditioning program reduce the differential between passive and active turnout in preprofessional dancers? Journal of Dance Medicine \& Science 18(4): 159-168.

35. Jenkins JB, Wyon M, Nevill A (2013) Can turnout measurements be used to predict physiotherapist-reported injury rates in dancers? Medical Problems of Performing Artists 28(4): 230-235.

36. Vaganova A (1945) Las bases de la danza clásica. Ediciones Centurión, Buenos Aires, Argentina.

37. Clippinger K (2005) Biomechanical considerations in turnout. In Solomon R, Minton S, Solomon J (Eds): Preventing Dance Injuries $\left(2^{\text {nd }}\right.$ edn). Human Kinetics, Champaign, USA, pp. 135-150.

38. Negus V, Hopper D, Briffa NK (2005) Associations between Turnout and Lower Dancers. J Orthop Sports Phys Ther 35(5): 307-318.

39. Koutedakis Y, Jamurtas A (2004) The dancer as a performing athlete: Physiological considerations. Sport Med 34(10): 651-661.

40. Weiss DS, Shah S, Burchette RJ (2008) A profile of the demographics and training characteristics of professional modern dancers. J Danc Med Sci 12(2): 41-46.

41. Welsh TM, Rodriguez M, Beare LW, Barton B, Judge T (2008) Assessing turnout in university dancers. J Dance Med Sci 12(4): 136-141.

42. Gupta A, Fernihough B, Bailey G, Bombeck P, Clarke A, et al. (2004) An evaluation of differences in hip external rotation strength and range of motion between female dancers and non-dancers. Br J Sports Med 38(6): 778-783.

43. Thomas H, Tarr J (2009) Dancers' Perceptions of Pain and Injury: Positive and Negative Effects. J Danc Med Sci 13(2): 51-59.

44. Clippinger K (2007) Dance anatomy and kinesiology. Human Kinetics, USA.

45. Fitt SS (1996) Dance kinesiology (2nd edn). Schirmer Books, USA.

46. Gontijo KN, Candotti CT, Feijo Gdos S, Ribeiro LP, Loss JF (2015) Kinematic evaluation of the classical ballet step "plie". J Danc Med Sci 19(2): 70-76.
47. Kravitz SR, Murgia CJ, Huber S, Saltrick K (1984) Biomechanical implications of dance injuries. In: Shell C (Eds) Dancer as Athlete. Human Kinetics, Champaign, USA.

48. Gilbert C, Gross M, Klug K (1998) Relationship between Hip External Rotation and Turnout Angle for the Five Classical Ballet Positions. Journal of Orthopedic \& Sports Physical Therapy 27(5): 339-347.

49. Howse AJG, Hancock SH (1988) Dance Technique and injury Prevention: Anatomical points relevant to Ballet. The muscles. A \& C Black, London, UK.

50. Gontijo KNS, Candotti CT, Feijó G dos S, Ribeiro LP, Loss JF (2016) Dynamic evaluation method of lower limbs joint alignment (MADAAMI) for dancers during the plié. Rev Bras Ciencias do Esporte 39(2): 148-159.

51. Chmelar RD, Shultz BB, Ruhling RO, Fitt SS, Johnson MB (1988) Isokinetic characteristics of the knee in female, professional and university, ballet and modern dancers. J Orthop Sports Phys Ther 9(12): 410-418.

52. Gelabert R (1980) Preventing dancer's injuries. Physician Sports med 8(4): 69-76.

53. Ryman R (1980) Training the dancer XI: The knee-Achilles heel of the body. Dance Can Magazine Spring p. 12-17.

54. Malcolm R (1996) The screw home mechanism and its implications for dancers. Impulse 4: 253-257.

55. Zarins B, Rowe CR, Harris B, Watkins MP (1983) Rotational motion of the knee. American Journal of Sports Medicine 11(3): 152-156.

56. Andreja Paley Picon SSF (2007) Análise antropométrica dos pés de praticantes de ballet clássico que utilizam sapatilhas de ponta. Rev Uniara 20(1): 7.

57. Picon AP, Costa PHL Da, Sousa F De, Sacco IDCN, Amadio AC (2002) Biomecânica e "ballet" clássico: uma avaliação de gravidez dinâmicas do "sauté" em primeira posição e da posição "en pointe" em sapatilhas de pontas. Rev Paul Educ Fís 16(1): 53-60.

58. Rietveld ABM (2013) Dancer's and musician's injuries. Clin Rheumatol 32(4): 425-434.

59. Bianchi P (2015) A Coordenação Motora como Dispositivo para a Criação : Umaabordagem somática na dança contemporânea. Rev Bras Est Presen 5(1): 148-168.

60. Meyer S (2011) As Metáforas do Corpo em Cena. Annablume, São Paulo, Brazil.

61. Louppe L (2012) Poética da Dança Contemporânea. Orfeu Negro, Lisboa, Europe.

62. Berthoz A (2000) The Brain's Sense of Movement. Giselle Weiss, Harvard University Press, USA. 
(C) (1) $\begin{aligned} & \text { This work is licensed under Creative } \\ & \text { Commons Attribution 4.0 License } \\ & \text { DOI: } 10.19080 / \text { JPFMTS.2018.02.555593 }\end{aligned}$
Your next submission with Juniper Publishers

will reach you the below assets

- Quality Editorial service

- Swift Peer Review

- Reprints availability

- E-prints Service

- Manuscript Podcast for convenient understanding

- Global attainment for your research

- Manuscript accessibility in different formats

( Pdf, E-pub, Full Text, Audio)

- Unceasing customer service

Track the below URL for one-step submission https://juniperpublishers.com/online-submission.php 